\title{
Um caso de midríase episódica benigna
}

Rita Ferreira, ${ }^{1}$ Margarida Moreira, ${ }^{1}$ Cristiana Martins, ${ }^{1}$ Luís Gomes ${ }^{2}$

\section{RESUMO}

Introdução: A anisocoria é um sinal de alarme que deve sempre implicar a exclusão de patologia neurológica grave, mas pode também ser a tradução de uma condição benigna e autolimitada, como o bloqueio colinérgico do esfíncter da pupila por exposição a substâncias parassimpaticolíticas ou quadros raros como a midríase episódica benigna.

Descrição do caso: Homem de 22 anos, agricultor, natural e residente em Aguçadoura. Pertencente a família nuclear, na fase I do ciclo de Duvall e classe média-alta de Graffar. Sem antecedentes pessoais ou familiares de relevo. Sem medicação habitual.

Apresentou-se na Consulta Aberta em junho de 2014 com um quadro de diminuição da acuidade visual e "sensação de visão enevoada" (sic) à direita. Negava história de contacto com tóxicos. Ao exame objetivo apresentava midríase unilateral à direita e diminuição dos reflexos pupilares fotomotores e do reflexo acomodação-convergência homolateral. Sem alterações dos movimentos extrínsecos dos olhos ou do posicionamento palpebral bilateral. Sem outras alterações ao exame físico. Foi referenciado ao serviço de urgência de oftalmologia onde realizou exame oftalmológico completo, testes farmacológicos, tomografia computorizada cerebral e angioressonância (angioRM) cerebral, que não apresentaram alterações.

Comentário: A ausência de outros sinais ou sintomas neurológicos, de alterações na angioRM e de contacto com tóxicos aponta para uma situação de midríase episódica benigna. Trata-se de um quadro raro, cuja fisiopatologia parece estar relacionada com disfunção autonómica.

É importante que o médico de família tenha conhecimento da sua existência, saiba fazer um correto exame e oriente adequadamente o doente para exclusão de outros diagnósticos diferenciais com diferentes prognósticos, tranquilizando e vigiando posteriormente o doente no que diz respeito à benignidade desta entidade e antecipando a possibilidade de recorrências.

Palavras-chave: Anisocoria; Midríase.

\section{INTRODUÇÃO}

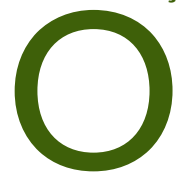

diâmetro pupilar (DP) depende do balanço entre a atividade do sistema nervoso parassimpático e simpático, que inervam os músculos esfíncter e dilatador da pupila, respetivamente. A assimetria do DP (anisocoria) é uma condição comum e as causas variam desde patologias graves que ameaçam a vida até aquelas perfeitamente benignas. ${ }^{1-3}$

Nos casos de anisocoria em que a pupila anormal está dilatada devem considerar-se como diagnósticos diferenciais: causas traumáticas que provocam lesão do músculo esfíncter da pupila, pupila de Adie, paralisia do III nervo craniano e exposição unilateral a agentes midriáticos. Deve sempre excluir-se patologia neurológica grave, nomeadamente tumores, aneurismas e infeções do sistema nervoso central. ${ }^{1-3}$ No entanto, a anisocoria por midríase unilateral pode também ser uma manifestação de um quadro mais raro de midríase episódica benigna, que cursa com episódios intermitentes de assimetria pupilar, na maioria das vezes sem outra sintomatologia neurológica. ${ }^{1-4}$

Este caso pretende sensibilizar para uma entidade benigna, que é a midríase episódica benigna. É necessário que o médico de família (MF) se encontre preparado para fazer a primeira abordagem de uma situação de anisocoria e proceda a uma articulação atempada com os cuidados de saúde secundários (CSS), sempre que necessário.

\section{DESCRIÇÃO DO CASO}

Expõe-se o caso de um utente do sexo masculino, de 22 anos, caucasiano, agricultor de profissão, natural e residente em Aguçadoura, com o 9. ${ }^{\circ}$ ano de escolaridade. Pertencente a uma família nuclear, na fase I do ciclo de Duvall, com classe média-alta de Graffar. Sem antecedentes pessoais de relevo. Sem medicação habitual e sem consumo habitual de tóxicos (álcool, tabaco ou drogas ilícitas). Desconhece antecedentes familiares de relevo.

Apresentou-se na Consulta Aberta da Unidade de Saúde Familiar (USF) das Ondas no dia 27/06/14 com um quadro de diminuição da acuidade visual e sensação de 
"visão enevoada" (sic) à direita com cerca de um dia de evolução. Referia ligeira fotofobia do olho direito. Negava cefaleias, dor orbitária, bem como náuseas, vómitos ou outras alterações gastrointestinais. Sem noção de febre, alterações comportamentais, da fala, da marcha ou disestesias. Negava igualmente trauma, história de consumo de drogas, tabaco ou medicação (incluindo colírios) ou qualquer contacto com novas substâncias químicas ou plantas no seu local de trabalho, referindo utilização de medidas de proteção individual.

Ao exame objetivo encontrava-se apirético, com sinais vitais estáveis, apresentando midríase unilateral à direita e diminuição dos reflexos pupilares fotomotores e do reflexo acomodação-convergência homolateral. Sem alterações dos movimentos extrínsecos dos olhos, ptose, proptose ou nistagmo. Acuidade visual de 8/10 no olho direito e 10/10 no olho esquerdo. Sem alterações no exame neurológico geral, nomeadamente a nível de coordenação e função motora, tonicidade muscular, sensibilidade e reflexos. Sem rigidez da nuca. Sem outras alterações de relevo no restante exame físico. Foi enviado ao Serviço de Urgência de Oftalmologia do Hospital Pedro Hispano, onde realizou exame oftalmológico completo, testes farmacológicos para a anisocoria e neuroimagiologia.

O exame oftalmológico à lâmpada de fenda excluiu patologia estrutural da íris, lesões do epitélio corneano, alterações a nível do disco ótico ou outras alterações do fundo ocular. O teste com pilocarpina tópica foi negativo. A tomografia computorizada (TC) e a angioressonância (angioRM) cerebral efetuadas não apresentaram alterações.

Três dias após o início dos sintomas, o quadro reverteu espontaneamente. O doente manteve vigilância em consulta de neuroftalmologia, com repetição de angioRM três meses depois, com resultado sobreponível à anterior, tendo, desta forma, tido alta da consulta hospitalar. Mantém acompanhamento por parte do seu MF, sem novos episódios semelhantes até ao momento.

\section{COMENTÁRIO}

No caso clínico apresentado, a ausência de outros sinais ou sintomas neurológicos associados à midríase (como ptose palpebral, diminuição dos movimentos extrínsecos dos olhos, sinais neurológicos focais), bem como a normalidade dos exames imagiológicos, apontam para uma etiologia benigna. ${ }^{1}$

Na abordagem deste caso é necessário ter presente um vasto leque de diagnósticos diferenciais que cursam com alterações pupilares de interesse neuroftalmológico, decorrentes maioritariamente de variações da normalidade, como anisocoria fisiológica, desnervação ou irritação (Quadro I), ${ }^{5}$ para além da midríase episódica benigna, descrita adiante.

Tendo em conta a profissão do utente, é também fundamental excluir o contacto com substâncias com ação midriática, nomeadamente agentes anticolinérgicos, muitas vezes encontrados em plantas e agentes químicos utilizados na agricultura e que é uma das causas mais frequentes de midríase. De entre as plantas que cursam com este efeito encontram-se várias pertencentes à família Solanaceae (Atropa belladonna, Hyosciamus níger, Scopolia carniolica, Lycium, Solanum, Datura, Brugmansi e Vestia foetida), ginseng, Lolium temulentum e Robina pseudoacacia. ${ }^{1}$ Produtos agroquímicos que contenham na sua constituição atropina (hiosciamima), hioscina (escopolamina), pirenzepina, telenzepina, tropicamida, ciclopentolato, benzatropina e ipratrópio, ou seus derivados, podem igualmente mimetizar este efeito. ${ }^{6}$

Desta forma, o diagnóstico diferencial de uma midríase deve ser fundamentado numa anamnese e exame físico cuidados. Ao alcance do MF encontram-se alguns testes cruciais na primeira abordagem e avaliação do doente, nomeadamente a medição dos DPs horizontais de ambos os olhos com o doente sentado, a olhar para o infinito, com iluminação normal da sala de exame e repetindo a mesma medição sob iluminação intensa, condições fotópicas (através de lanterna acesa colocada próximo de ambos os olhos) e na obscuridade, condições mesópicas (com luz da sala apagada, incidindo luz de fraca intensidade, oblíqua e inferiormente aos olhos do doente). Em caso de ausência de alterações, as variações dos DPs sob os três níveis de luminosidade são iguais em ambos os olhos. Os reflexos pupilares fotomotores pesquisam-se apontando direta e frontalmente a luz forte da lanterna sobre a pupila de cada olho individualmente, devendo as contrações pupilares fotomotoras direta e consensual de ambos os olhos serem iguais, em casos de normalidade. Por fim, é também importante avaliar a sincinesia acomodação-convergência e, para tal, devem ser medidos os DPs, com iluminação normal, quando o doente olha para o infinito e comparados com os DPs no olhar para perto $(15-20 \mathrm{~cm}$ à sua frente). A redução dos DPs através da sincinesia deve ser igual bilateralmente e menor do que a conseguida com o estímulo fotomotor. ${ }^{5}$

Em caso de alteração em algum dos testes referidos, o doente deve ser orientado com a maior brevidade possível para oftalmologia para que se proceda à exclusão de 
QUADRO I. Diagnósticos diferenciais de midríase benigna.

\begin{tabular}{|c|c|}
\hline Diagnósticos diferenciais & Sinais/Sintomas \\
\hline Anisocoria essencial ou fisiológica & $\begin{array}{l}\text { - Diferença entre os DPs bilateralmente < 0,5mm e com pouca variação com os } \\
\text { níveis de iluminação } \\
\text { - Funções visuais, pupilares fotomotoras e sincinesia acomodação-convergência } \\
\text { sem alterações } \\
\text { - Posicionamento palpebral e movimentos extrínsecos dos olhos sem alterações }\end{array}$ \\
\hline $\begin{array}{l}\text { Anisocoria por paralisia parassimpática } \\
\text { pré-ganglionar (paralisia III nervo) }\end{array}$ & $\begin{array}{l}\text { - Midríase unilateral com pupila dilatada sem resposta a nenhum estímulo } \\
\text { fotomotor ou reflexo de acomodação-convergência } \\
\text { - Visão conservada para longe e diminuída para perto } \\
\text { - Grande variação da anisocoria com diferente luminosidade (anisocoria maior em } \\
\text { condições fotópicas) } \\
\text { - Sensibilidade à pilocarpina } 1 \% \\
\text { - Em casos de paralisia completa do III nervo: ptose da pálpebra superior, estrabismo }\end{array}$ \\
\hline $\begin{array}{l}\text { Anisocoria por paralisia parassimpática } \\
\text { pós-ganglionar: } \\
\text { - Pupila de Adie }\end{array}$ & $\begin{array}{l}\text { Pupila de Adie: } \\
\text { - Midríase aguda unilateral + deficiência da visão para perto; pode bilateralizar-se } \\
\text { após algumas semanas } \\
\text { - Mais em mulheres } 20-40 \text { anos } \\
\text { - Grande variação da anisocoria com diferente luminosidade, maior em condições } \\
\text { fotópicas (não reage a estímulos luminosos) } \\
\text { - Hipersensibilidade à pilocarpina } 0,125 \% \\
\text { Anisocoria medicamentosa: } \\
\text { - Midríase grande, sem resposta a nenhum estímulo } \\
\text { - Deficiência da visão ao perto } \\
\text { - Sem anomalia palpebral ou da motilidade ocular extrínseca } \\
\text { - Desaparece } 5-8 h \text { após o contacto com parassimpaticolítico (se a droga for } \\
\text { atropina pode demorar dias a desaparecer) }\end{array}$ \\
\hline $\begin{array}{l}\text { Anisocoria por paralisia simpática } \\
\text { (Síndroma de Claude Bernard - Horner) }\end{array}$ & $\begin{array}{l}\text { - Quadro uni e ipsilateral de pequena miose e ligeira ptose palpebral } \\
\text { - Diagnóstico diferencial difícil por surgir mais frequentemente em pessoas com íris } \\
\text { escura e idade avançada } \\
\text { - Resposta pupilar a todos os estímulos fotomotores e de acomodação- } \\
\text {-convergência apesar de redilatação lenta }\end{array}$ \\
\hline Síndroma Pourfour du Petit & $\begin{array}{l}\text { - Síndroma oposta à síndroma de Horner, causada por irritação nervosa simpática } \\
\text { cervical } \\
\text { - Midríase e exoftalmia }\end{array}$ \\
\hline
\end{tabular}

patologia estrutural ou funcional da íris. Por outro lado, após verificação da integridade do epitélio corneano do doente, bem como da exclusão de antecedentes de trauma, inflamações e infeções oculares, frequentemente percebidos na colheita de uma história clínica completa, alguns testes com colírios e exames de imagem podem auxiliar no diagnóstico diferencial de anisocoria. ${ }^{5}$

A realização da prova da pilocarpina é um importante método de diagnóstico. Se positivo (diminuição do DP da pupila midriática em relação ao olho contralateral), este teste (a $0,125 \%)$ permite suspeitar de pupila de Adie ou de paralisia do III nervo (a 1\%). Por outro lado, se for negati- vo (como no caso em estudo) podemos estar na presença de uma possível contaminação ocular com antagonistas muscarínicos ou de midríase episódica benigna. ${ }^{5}$

Neste caso, a neuroimagiologia foi igualmente importante para a exclusão de outros diagnósticos diferenciais e a ausência de alterações de relevo reforçou a benignidade do quadro. ${ }^{5}$

Desta forma, com uma anamnese e um exame físico do doente sem outras alterações, suportados por um estudo imagiológico inocente e evolução clínica favorável com desaparecimento espontâneo da midríase unilateral, foi efetuado o diagnóstico de midríase episódica benigna uni- 
lateral. Esta situação é um quadro raro, com poucos estudos. Julga-se que poderá compreender um grupo heterogéneo de condições que resultam da insuficiência parassimpática do esfíncter da pupila nuns casos e da hiperatividade simpática do dilatador da pupila noutros, mas a fisiopatologia não é clara. ${ }^{3,7-8}$ Já foi descrita associada à enxaqueca, mas pode ocorrer em pessoas saudáveis e perfeitamente assintomáticas. ${ }^{9}$ É mais frequente em jovens, sobretudo do sexo feminino. ${ }^{2,10}$ Os episódios tendem a recorrer, geralmente no mesmo olho, mas a localização pode variar, podendo durar horas a dias. ${ }^{11}$ Podem ser acompanhados por visão enevoada, dor orbitária, cefaleia ou fotofobia. ${ }^{7} \mathrm{O}$ prognóstico é benigno. ${ }^{8}$ É importante que o MF tenha conhecimento desta patologia, saiba fazer um correto exame oftalmológico e neurológico e proceder a uma correta e rápida articulação com os cuidados hospitalares na presença de sinais de alarme e sempre que surjam dúvidas no que se refere ao diagnóstico e orientação terapêutica. Por fim, cabe ao MF vigiar e tranquilizar o doente no que diz respeito à benignidade do seu quadro clínico e antecipar possíveis recorrências.

\section{REFERÊNCIAS BIBLIOGRÁFICAS}

1. Calado C, Pereira A, Moço C, Silva M, Maio J. Midríase acidental por contacto com Brugmansia versicolor Lagerh [Accidental mydriasis from contact with Brugmansia versicolor Lagerh]. Acta Pediatr Port. 2008;39(4):155-7. Portuguese

2. Chadha V, Tey A, Kearns P. Benign episodic unilateral mydriasis. Eye. 2007;21 (1):118-9.

3. Balaguer-Santamaría JA, Escofet-Soteras C, Chumbe-Soto G, Escribano-Soto
J. Midriasis unilateral benigna episódica: caso clínico en un niño [Benign episodic unilateral midriasis: a report of a case in a child]. Rev Neurol. 2000;31(8); 743-5. Spanish

4. Antonio-Santos AA, Santos RN, Eggenberg ER. Pharmacological testing anisocoria. Expert Opin Pharmacother. 2005;6(12):2007-13.

5. Rodrigues-Alves CA. Pupila neuro-oftalmológica. Rev Sinopse Oftalmol. 1999;1(2). Available from: http://www.moreirajr.com.br/revistas.asp?id_ materia $=1249 \&$ fase $=$ imprime. Portuguese

6. Sá PC. Sistema colinérgico. In Guimarães S, Moura D, Silva PS, editors. Terapêutica medicamentosa e suas bases farmacológicas. $5^{\text {a }}$ ed. Porto: Porto Editora; 2006. p. 234-9. ISBN 9720060298

7. Jacobson DM. Benign episodic unilateral mydriasis: clinical characteristics. Ophthalmology. 1995;102(11):1623-7.

8. Johnston JA, Parkinson D. Intracranial sympathetic pathways associated with the sixth cranial nerve. J Neurosurg. 1974;40(2):236-43.

9. Edelson RN, Levy DE. Transient benign unilateral pupillary dilation in young adults. Arch Neurol. 1974;31(1):12-4.

10. Bek S, Genc G, Demirkaya S, Eroglu E, Odabasi Z. Ophthalmoplegic migraine. Neurologist. 2009;15(3):147-9.

11. Cox TA, Daroff RB. Pupillary and eyelid abnormalities. In Bradley WG, Daroff RB, Fenichel GM, Jankovic J, editors. Neurology in clinical practice. 5th ed. Philadelphia: Butterworth Heinemann; 2008. p. 225-32.

\section{CONFLITOS DE INTERESSE}

Os autores declaram não possuir quaisquer conflitos de interesse.

\author{
ENDEREÇO PARA CORRESPONDÊNCIA \\ Rita Ferreira \\ Rua da Praia, n. 186 - Fieiro - Aguçadoura - 4495-031 Póvoa de Varzim \\ E-mail: ritarmferreira@gmail.com
}

Recebido em 22-11-2014

Aceite para publicação em 11-06-2015

Artigo escrito ao abrigo do novo acordo ortográfico.

\section{ABSTRACT}

\section{A CASE OF BENIGN EPISODIC MYDRIASIS}

Introduction: Anisocoria requires exclusion of serious neurological pathology but it may also be a benign and self - limiting condition, as in cholinergic blockade of the pupillary sphincter by parasympatheticolytic substances or in rare conditions such as benign episodic mydriasis.

Case description: A 22 year-old male farm worker presented in June 2014 with decreased visual acuity and 'foggy vision' in the right eye. There was no history of contact with toxins. Examination revealed unilateral mydriasis of the right pupil and decrease in the pupillary light reflex and in the ipsilateral accommodation - convergence reflex. No changes were noted in extra-ocular movements or in the position of the eyelids. No other abnormalities were found on physical examination. The patient was referred to the Ophthalmology Emergency Department where he underwent further examination that did not reveal additional findings.

Comment: A negative history of contact with toxins, the absence of other neurological signs or symptoms, and a normal magnetic resonance angiography study support a diagnosis of benign episodic mydriasis. This is a rare condition, which appears to be related to autonomic dysfunction. It is important for family physicians to be aware of this condition, to know how to perform a correct clinical examination, and to refer the patient for additional testing to exclude other diagnoses. Patients require reassurance that the condition is benign and proper follow-up for possible recurrence.

Keywords: Mydriasis; Anisocoria. 